\section{Public Health Genomics}

Public Health Genomics 2013;16:208-214

DOI: $10.1159 / 000353460$
Received: February 26, 2013

Accepted after revision: June 3, 2013 Published online: July 25, 2013

\title{
Family History: Impact on Coronary Heart Disease Risk Assessment beyond Guideline-Defined Factors
}

\author{
Q. Hasanaj ${ }^{\mathrm{a}}$ B.J. Wilson ${ }^{\mathrm{a}} \quad$ J. Little $^{\mathrm{a}} \quad$ Z. Montazeri $^{\mathrm{a}}$ \\ J.C. Carroll ${ }^{b}$ On behalf of the CIHR Emerging Team in Genomics in Screening \\ ${ }^{a}$ Department of Epidemiology and Community Medicine, University of Ottawa, Ottawa, Ont., and bepartment of \\ Family and Community Medicine, Mount Sinai Hospital, University of Toronto, Toronto, Ont., Canada
}

\section{Key Words}

Clinical validity $\cdot$ Coronary heart disease $\cdot$ Discrimination .

Family history $\cdot$ Reclassification

\begin{abstract}
Objective: Family history $(\mathrm{FH})$ provides insights into the effects of shared genomic susceptibilities, environments and behaviors, making it a potentially valuable risk assessment tool for chronic diseases. We assessed whether coronary heart disease (CHD) risk assessment is improved when $\mathrm{FH}$ information is added to other clinical information recommended in guidelines. Methods: We applied logistic regression analyses to cross-sectional data originally obtained from a UK study of women who delivered a live-born infant between 1951 and 1970. We developed 3 models: Model 1 included only the covariates in a guideline applicable to the population, Model 2 added FH to Model 1, and Model 3 included a fuller range of risk factors. For each model, its ability to discriminate between study subjects with and those without CHD was evaluated and its impact on risk classifica-
\end{abstract}

\begin{tabular}{ll}
\hline KARGER & $\begin{array}{l}\text { ( } 2013 \text { S. Karger AG, Basel } \\
1662-4246 / 13 / 0165-0208 \$ 38.00 / 0 \quad \text { Karger }\end{array}$ \\
E-Mail karger@karger.com & $\begin{array}{l}\text { This is an Open Access article licensed under the terms of the } \\
\text { www.karger.com/phg }\end{array}$ \\
& $\begin{array}{l}\text { Creative Commons Attribution-NonCommercial 3.0 Un- } \\
\text { ported license (CC BY-NC) (www.karger.com/OA-license), } \\
\text { applicable to the online version of the article only. Distribu- } \\
\text { tion permitted for non-commercial purposes only. }\end{array}$
\end{tabular}

tion examined using the net reclassification index. Results: $\mathrm{FH}$ was an independent risk factor for $\mathrm{CHD}$ (odds ratio $=1.7$, $95 \%$ confidence interval $=1.26-2.47$ ) and improved discrimination beyond guideline-defined clinical factors $(p<0.0006)$. However, the difference in the area under the curve of $2.8 \%$ and the extent of patient reclassification resulting from the inclusion of FH were small $(p=0.11)$. Conclusion: While FH were a significant independent risk factor for CHD, it added little to risk factors typically included in guidelines.

(c) 2013 S. Karger AG, Basel

\section{Introduction}

The completion of the Human Genome Project and advances in genomic techniques are changing our understanding of disease [1-3] and have led to the attractive concept of personalized medicine. To date, very few genomic tests with an adequate evidence base are available for general application $[4,5]$. Family history $(\mathrm{FH})$ has attracted attention for its potential as a risk assessment tool 
which might be easily applied across many areas of health care [6-8]. In clinical genetics, $\mathrm{FH}$ information is the principal tool for risk assessment, and has also been shown to be strongly associated with the risk of many common complex diseases as well as Mendelian single gene disorders. A person's FH reflects 'the consequences of genetic susceptibilities, shared environment, and common behaviors' [7]. However, although FH is considered 'one of the oldest diagnostic tools in medicine' [7], its performance when applied widely in risk assessment requires rigorous evaluation [8]. Many publications cite relative risk as the measure of association between $\mathrm{FH}$ and risk of disease; however, while relative risk quantifies an association at the population level, it is not necessarily helpful at the individual patient level, where metrics such as predictive value are more relevant [9]. Only a few published studies assess how well FH performs in risk assessment of individual patients drawn from general clinical populations [10-12].

These issues were highlighted in the consensus panel statement emerging from the 2009 NIH State-of-the-Science Conference on Family History and Improving Health [13]. The consensus panel concluded that FH information alone had limited predictive validity for complex diseases, and that 'future ... efforts should evaluate family history in combination with genetic and environmental variables, for its predictive value and its potential role in improving patient outcomes' [13].

Empirical studies evaluating FH in this way ideally require longitudinal data in which the full range of information on risk factors and $\mathrm{FH}$ are captured at baseline, coupled with appropriate measures of disease outcome. While there are examples of this approach, such as the Multi-Ethnic Study of Atherosclerosis prospective cohort study [14], investigations of this kind will take, at a minimum, 5-10 years to generate adequate data for analysis and will be difficult to justify for FH analyses alone. Few existing longitudinal studies are likely to have sufficiently complete data about $\mathrm{FH}$, risk factors that are typically included in guidelines, and disease incidence or mortality to allow adequate secondary analyses. Cross-sectional analyses, though not directly investigating prediction, may offer useful insight. Therefore, we undertook an analysis of a cross-sectional study to examine the extent to which risk stratification in a complex disorder, coronary heart disease (CHD), was improved when $\mathrm{FH}$ was added to standard risk factor information specified in a clinical practice guideline. This analysis was of particular interest because assessments of the value of genetic variants for cardiovascular disease prediction (online supple- mentary table 1 ; for all supplementary material, see www. karger.com/doi/10.1159/000353460) have shown very little improvement in disease prediction.

\section{Subjects and Methods}

\section{Study Design and Participants}

This study was a secondary analysis of data from the Aberdeen Study of Cardiovascular Health in Women (ASCHW), a retrospective cohort study originally designed to examine the association between hypertensive diseases of pregnancy and cardiovascular outcomes in later life [15]. Briefly, the ASCHW study compared 3 groups of women who had delivered their first live singleton infant between 1951 and 1970 in Aberdeen, Scotland: one group diagnosed with pre-eclampsia or eclampsia, another group diagnosed with gestational hypertension and a control group with neither. The 2 latter groups were matched for age and year of delivery with the pre-clampsia/eclampsia group. Women with chronic hypertension were excluded. Eligible participants were identified through the Aberdeen Maternal and Neonatal Databank and traced up to 1997 using their United Kingdom National Health Service number. Those still resident in North East Scotland were invited to complete a health questionnaire and undergo a detailed clinical examination [15]. Study participants and research nurses were blind to the study group status [15]. Of 3,593 eligible participants, family physicians gave permission to contact 1,876 women. Of these, 1,312 completed the survey and 992 attended the clinical examination (online suppl. fig. 1) [15], of whom all but 19 participants consented to blood draw, leaving 973 participants.

For this analysis, we used cross-sectional data on the risk factors of interest (including $\mathrm{FH}$ ) captured at the follow-up point of the study, at which point presence or absence of CHD was also ascertained. The risk factors of interest were those defined in a clinical practice guideline (the 'JBS 2' [16]) applicable to a British population. JBS 2 is based on the Framingham risk reclassification algorithm $[17,18]$. We developed 3 logistic regression models intended to discriminate between women with and without CHD. Model 1: used only the standard risk factors specified in JBS 2, Model 2: added FH information to these risk factors and Model 3: added all variables available in our dataset which independently improved the discriminatory accuracy. Approval for the original study was granted by the Grampian Health Board and University of Aberdeen Joint Ethical Committee and for the current analysis by the Ottawa Hospital Research Ethics Board.

\section{Variables}

The primary outcome was $\mathrm{CHD}$, which was considered present if participants had: (a) angina or possible myocardial infarction as defined by the Rose criteria [19] (questionnaire data) and/or (b) one or more EKG abnormalities consistent with ischemic heart disease (clinical examination data). EKGs were obtained by the research nurses at the follow-up clinical examination and were blindly coded according to the Minnesota system [20]. They were classified as CHD if they showed either Q/QS pattern changes and/or other coded 'ischemic' changes.

The JBS 2 specifies the following variables for risk classification for cardiovascular disease: age, systolic blood pressure, ratio of total cholesterol to high-density lipoprotein, smoking status, and 
Table 1. Comparison of final analytical sample according to $\mathrm{CHD}$

\begin{tabular}{|c|c|c|c|}
\hline Characteristics & $\mathrm{CHD}^{\mathrm{a}}$ & No $\mathrm{CHD}^{\mathrm{b}}$ & $\chi^{2}$ and $t$ test \\
\hline \multicolumn{4}{|l|}{ Age group } \\
\hline $0-49$ years & $6(2.8 \%)$ & $66(9.0 \%)$ & \multirow[t]{3}{*}{0.002} \\
\hline $50-59$ years & $69(32.5 \%)$ & $269(36.6 \%)$ & \\
\hline 60 years and older & $137(64.6 \%)$ & $398(54.2 \%)$ & \\
\hline Attained higher education & $74(34.9 \%)$ & $257(35.0 \%)$ & 0.96 \\
\hline Social class categories, I-III non-manual & $135(63.6 \%)$ & $484(66.0 \%)$ & 0.52 \\
\hline Exercise & $119(56.1 \%)$ & $555(75.7 \%)$ & 0.0001 \\
\hline \multicolumn{4}{|l|}{ Alcohol intake } \\
\hline 0 units/weeks & $97(45.7 \%)$ & $352(48.0 \%)$ & \multirow[t]{3}{*}{0.65} \\
\hline $1-14$ units/weeks & $107(50.4 \%)$ & $361(49.2 \%)$ & \\
\hline 14+ units/weeks & $8(3.7 \%)$ & $20(2.7 \%)$ & \\
\hline Smoking & $28(13.2 \%)$ & $108(14.7 \%)$ & 0.57 \\
\hline \multicolumn{4}{|l|}{ BMI } \\
\hline Normal range & $60(28.3 \%)$ & $278(37.9 \%)$ & \multirow[t]{3}{*}{0.006} \\
\hline Overweight & $88(41.5 \%)$ & $300(40.9 \%)$ & \\
\hline Obese & $64(30.1 \%)$ & $155(21.1 \%)$ & \\
\hline Family history & $106(50.0 \%)$ & $270(36.8 \%)$ & 0.0006 \\
\hline Diabetes & $10(4.7 \%)$ & $21(2.8 \%)$ & 0.18 \\
\hline \multicolumn{4}{|l|}{ ASCHW group } \\
\hline Control & $43(20.2 \%)$ & $153(20.8 \%)$ & \multirow[t]{3}{*}{0.21} \\
\hline Hypertention & $65(30.6 \%)$ & $267(36.4 \%)$ & \\
\hline Eclampsia and Pre-eclampsia & $104(49.0 \%)$ & $313(42.7 \%)$ & \\
\hline \multicolumn{4}{|l|}{ Cholesterol, mmol/l } \\
\hline Total & $6.31 \pm 1.24$ & $6.23 \pm 1.17$ & 0.39 \\
\hline HDL & $1.40 \pm 0.36$ & $1.47 \pm 0.39$ & 0.01 \\
\hline \multicolumn{4}{|l|}{ Blood pressure mm Hg } \\
\hline Systolic & $147.7 \pm 28.9$ & $142.4 \pm 25.5$ & 0.01 \\
\hline Diastolic & $80.2 \pm 12.2$ & $80.1 \pm 10.4$ & 0.92 \\
\hline
\end{tabular}

diabetic status. We used these risk factors in our model development and did not apply the JBS 2 formula directly to our dataset. We ascertained $\mathrm{FH}$ from the survey responses. We defined positive $\mathrm{FH}$ as 'diagnosis of heart disease before the age of 60 in either parent or any siblings' and dichotomized it into present (at least one affected first-degree relative) or absent (no affected first-degree relative). We also included variables relevant to the description of the sample and those which were potential confounders or effect modifiers: exercise, body mass index, alcohol intake, diastolic blood pressure, educational attainment, socioeconomic status, and original ASCHW grouping (pre-eclampsia/eclampsia, gestational hypertension, neither) (online suppl. table 2 ).

\section{Statistical Analysis}

Standard descriptive statistics were used to compare the groups with and without CHD. We used $\chi^{2}$ and t tests to assess the differences between the groups. For the 3 models, we assessed linearity of continuous variables using LOESS smoothing on the logit scale. We compared the performance of Model 2 versus Model 1 and Model 3 versus Model 1 using likelihood ratios, c-statistic and receiver-operating curves. The c-statistic (representing the area under the receiver-operating curves) indicates a model's performance in correctly identifying the status of each subject in a sample with respect to having or not having the attribute of interest: in this study, correctly identifying those who had CHD and those who did not [21]. We also used risk reclassification tables to compare Models 2 and 3 with Model 1, using the net reclassification index (NRI) as a summary measure [21]. The NRI estimates the overall improvement in reclassification between models and quantifies the correct movement of individuals to higher and lower risk categories [21]. To aid interpretation of the reclassification analysis, we selected 2 probability cut-off points for having CHD resulting in 3 risk strata (low, $<20 \%$; intermediate, $20-50 \%$; and high, $>50 \%$ ). These were chosen to illustrate the performance of the models and were not informed by specific clinical criteria. Analyses were performed using Statistical Analysis Software 9.2 (SAS Institute, Cary, N.C., USA). 


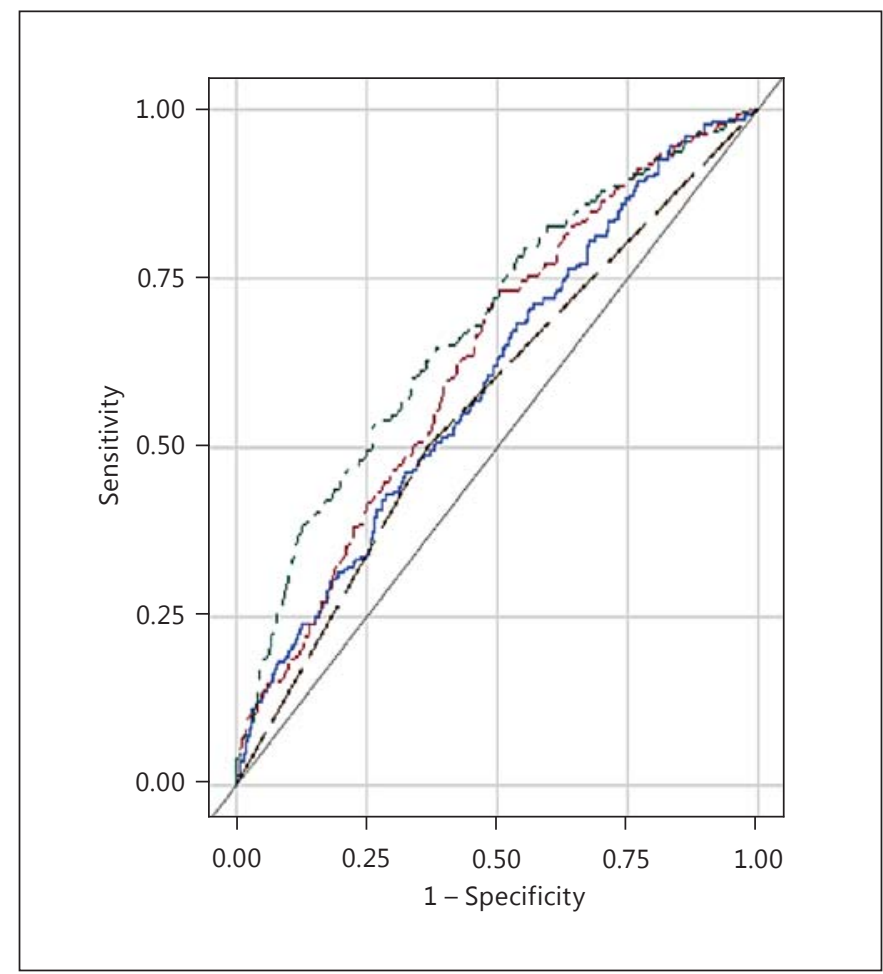

Fig. 1. Receiver-operating curves for the models considered.

\section{Results}

Of the 973 participants, 28 were excluded due to missing data on one or more of the variables considered in our models, resulting in 945 (97\%) respondents included in the final analysis.

Descriptive statistics are presented in table 1. A total of 212 participants (22.4\%) fulfilled the criteria for CHD. Compared to the group without $\mathrm{CHD}$, the $\mathrm{CHD}$ group was slightly older (64.6\% in the oldest age category), had lower self-reported levels of physical activity, was more likely to be obese, had lower mean high-density lipoprotein and higher mean systolic blood pressure, and was more likely to report a positive FH. There were no statistically significant differences between the groups in attainment of higher education, social class, alcohol intake, diastolic blood pressure, total cholesterol, diabetes, original ASCHW group, or current self-reported smoking status.

For all models, the regression coefficients for age, systolic blood pressure, total cholesterol, and high-density lipoprotein were statistically significant. The c-statistic for Model 1 was 0.603 . For Model 2, the regression coefficient for FH was highly significant $(\mathrm{p}<0.0006$, odds ra-

Family History in Coronary Heart Disease Risk Assessment tio $(\mathrm{OR})=1.70,95 \%$ confidence interval $(\mathrm{CI})=1.26-$ 2.47 ), and the c-statistic was 0.631 . Of the additional variables available for inclusion in Model 3, only one (exercise) was retained because it satisfied the threshold $p$ value. The regression coefficient for $\mathrm{FH}$ remained significant $(\mathrm{p}<0.0021, \mathrm{OR}=1.67,95 \% \mathrm{CI}=1.21-2.31)$ and for exercise was highly significant $(\mathrm{p}<0.0001, \mathrm{OR}=0.40,95 \%$ $\mathrm{CI}=0.28-0.55)$. The c-statistic for Model 3 was 0.681 .

The likelihood ratio comparing Models 1 and 2 was $11.654(\mathrm{p}<0.0006)$ and comparing Models 1 and 3 was 40.034 ( $\mathrm{p}<0.0001)$, suggesting that both the FH and exercise variables improved the overall fit of the basic model. The results are summarized in figure 1.

The reclassification results for Model 2 versus 1 are summarized in table 2 . Across the entire sample, 18 participants were reclassified in the correct direction with Model 2: 1 individual with CHD was reclassified from a lower risk to a higher risk stratum (implying she was a false negative under Model 1), and 17 individuals without CHD were reclassified from a higher risk to a lower risk stratum (implying they were false positives under Model 1). Four participants were reclassified incorrectly: 2 with CHD were reclassified to lower risk strata (therefore, to false negative under Model 2), and 2 who did not have $\mathrm{CHD}$ were reclassified to higher risk strata (to false positive under Model 2). The NRI estimate was 0.015, statistically nonsignificant ( $\mathrm{p} \geq 0.119$ ).

The reclassification results for Model 3 versus 1 are summarized in table 2 . Seventy-eight women were correctly reclassified: 14 with $\mathrm{CHD}$ to higher risk strata (from false negative under Model 1 to true positive) and 64 without CHD to lower risk strata (from false positive under Model 1 to true negative). A total of 25 were incorrectly reclassified, 10 with $\mathrm{CHD}$ to lower risk strata (from true positive to false negative under Model 3) and 15 without CHD to higher risk strata (from true negative to false positive under Model 3). The NRI estimate was 0.085 ( $p<0.001)$.

\section{Discussion}

These analyses suggest that $\mathrm{FH}$ is an important independent risk factor associated with CHD in the sample of women studied. In principle, therefore, it might improve predictive models over and above guideline-defined risk factors. Our findings are consistent with another crosssectional study of $\mathrm{FH}$ and cardiovascular risk assessment. Scheuner et al. [11] investigated the improvements in identification of individuals with advanced coronary artery calcification (a proxy for cardiovascular disease) 
Table 2. Reclassification results for the models considered

\begin{tabular}{|c|c|c|c|c|c|c|c|}
\hline Model 1 & & $\begin{array}{l}<0.2 ; \\
\text { low risk }\end{array}$ & $\begin{array}{l}0.2-0.5 \text {; } \\
\text { intermediate } \\
\text { risk }\end{array}$ & $\begin{array}{l}>0.5 \\
\text { high risk }\end{array}$ & $\begin{array}{l}<0.2 ; \\
\text { low risk }\end{array}$ & $\begin{array}{l}0.2-0.5 \text {; } \\
\text { intermediate } \\
\text { risk }\end{array}$ & $\begin{array}{l}>0.5 ; \\
\text { high risk }\end{array}$ \\
\hline \multirow[t]{2}{*}{$\mathrm{CHD}(\mathrm{n}=212)$} & $<0.2$; low risk & 1 & 0 & 0 & 0 & 1 & 0 \\
\hline & $0.2-0.5$; intermediate risk & 2 & 208 & 1 & 10 & 188 & 13 \\
\hline \multirow[t]{3}{*}{ No CHD $(\mathrm{n}=733)$} & $<0.2$; low risk & 7 & 2 & 0 & 4 & 5 & 0 \\
\hline & $0.2-0.5$; intermediate risk & 17 & 707 & 0 & 64 & 650 & 10 \\
\hline & $>0.5$; high risk & 0 & 0 & 0 & 0 & 0 & 0 \\
\hline
\end{tabular}

gained by adding $\mathrm{FH}$ to a multivariate model which predicts global cardiovascular disease risk. They showed that adding simple FH information produced highly statistically significant improvements to the model, although the study was limited by the use of a surrogate outcome.

However, given that a binary risk stratification system is likely to be correct for $50 \%$ of subjects simply due to chance, the observed area under the curve (AUC) values for our models (under 0.7) represent a modest performance. Our findings are consistent with the longitudinal analyses of incident CHD and cardiovascular disease outcomes recently reported by the Multi-Ethnic Study of Atherosclerosis study investigators [14]. In analyses confined to individuals at intermediate risk at baseline, this study observed that FH improved the AUC from 0.623 (Framingham Risk Score) to 0.675 for both CHD and cardiovascular disease outcomes.

This throws into question the clinical relevance of the additional 'information value' of FH and supports the contention that risk factors strongly associated with disease incidence do not necessarily translate into strong predictors of disease at an individual level, and, therefore, they require further evaluation before being considered as screening or predictive tests $[22,23]$. The combination of risk factors, each with moderate discriminatory accuracy, does not necessarily result in additive improvements in predictive ability. If the findings of the MultiEthnic Study of Atherosclerosis study, and our own, are replicated, then it would reinforce the importance of following up analytical epidemiological studies (which generate relative risk estimates) with clinical studies which evaluate the predictive accuracy of risk factors when used in individual patients. Differences in absolute risk between individual patients with or without a positive $\mathrm{FH}$ may be more meaningful and accurate than multiplicative increases.

It has been suggested that performing receiver-operating curve analyses is an appropriate first step in examining the incremental improvement in risk discrimination conferred by a risk factor, and that a clinically meaningful change in AUC must be present to justify moving on to assessing impact on risk reclassification [24]. However, there is no single benchmark for 'clinically significant change' in AUC, since the latter must depend on the consequences of the change in classification for the population in question. The 'utility threshold' for a change in AUC depends on the absolute benefits costs at a population level which follow from improvement in prediction [25]. A first step is to quantify the net reclassification of risk for a target population, not only in terms of magnitude, but also in direction, and in differential effects on subpopulations. Allowing for the preliminary nature of the analyses, the data presented here suggest that adding FH achieved small overall shifts in subject risk classification (magnitude), with net fewer false positives (direction), mainly in unaffected women (differential population effects). If these results are replicated, it would suggest that the benefits from including FH in the model accrue from reductions in intervention in people for whom it is not indicated. Although this point may be counter-intuitive, in that risk, models are probably unconsciously perceived as being useful for identifying 'positive' risk (case finding); it has been made recently by other authors [26]. A holistic approach to assessing benefits and costs needs to include modeling impacts of reduction in false positive rates, not just the identification of more cases. Risk reclassification analyses, linked with decision-modeling 
approaches, provide a basis for quantifying the population impacts of altering risk stratification systems through changes in clinical management, patient behavior and use of resources.

\section{Strengths and Limitations}

The original ASCHW study examined the association between hypertensive disease of pregnancy and the development of CHD later in life. As a result, ASCHW oversampled women with a history of hypertensive diseases of pregnancy, and these were demonstrated to be positively associated with later cardiovascular disease [27]. This is probably the reason for the high prevalence of $\mathrm{CHD}$ in our sample (22\%).

The original cohort study was carefully conducted, and the original coding and case definitions were subject to careful quality assurance [28-30]. The outcome assessments were based on validated instruments: the WHO (Rose) Angina Questionnaire [19, 31] was developed for self-report use in epidemiological studies, although it is likely to under-ascertain cases in women as its sensitivity and positive predictive value for angina is limited in this group [32,33]. The positive predictive value of MI by Rose criteria is not known in this group. In a prospective cohort study consisting of 8,434 British women, OwenSmith et al. [34] investigated the 5-year mortality rate of Rose MI. The results showed that the 5-year mortality rate from all causes was $\mathrm{OR}=2.1,95 \% \mathrm{CI}=1.0-4.1$ for women with Rose MI along with ischemic heart disease, and $\mathrm{OR}=2.3,95 \% \mathrm{CI}=1.3-3.8$ for women with Rose MI without ischemic heart disease compared to women who did not have Rose MI [34]. Despite its limitations, the Rose Angina Questionnaire is a well known and widely used outcome criterion in epidemiological studies [31]. The Rose Angina Questionnaire lacks 'a gold standard' for validating its results; in its absence, EKG, expert opinion, angioplasty and exercise thallium scans have been used as alternatives [31]. The use of EKG results along with Rose results, therefore, should address some of the limitations. The EKG data were obtained under carefully controlled examination conditions and coded using standardized methods [20], although it is also likely that this under-ascertained CHD cases [35]. However, some of the variables of interest, e.g. diabetes status, were captured by self-report rather than objective clinical measures [20]. It is unlikely that the frequency of the misclassification errors (false negatives) was systematically different for individuals with and without a positive $\mathrm{FH}$ of $\mathrm{CHD}$. The analyses were, however, inevitably constrained by the design of the original study.

Family History in Coronary Heart Disease Risk Assessment
A major issue is that this was a cross-sectional analysis: although the data were derived from a cohort study, the variables of interest were only available from the followup component. Thus, the analyses here evaluated the discriminatory accuracy of $\mathrm{FH}$ and other risk factors in detecting current disease, not predicting future disease. It is unclear how closely these cross-sectional findings resemble a predictive scenario. In order to properly examine disease prediction, it is necessary to have a longitudinal approach, in which the full range of variables is available at the 'exposure' time point as well as a sufficient number of outcome events to offer sufficient statistical power for meaningful analysis.

The original dataset did not allow us to examine the full range of cardiovascular disease outcomes, including stroke. The JBS 2 guideline includes stroke in the definition of cardiovascular disease, whereas our outcome excluded it. It is plausible that the overall AUC would have been higher for the combined outcome rather than for CHD alone, but this does not, in itself, invalidate the evaluation of the incremental discriminatory accuracy of FH when added to standard risk factors. Furthermore, we did not apply the JBS 2 models directly to our dataset; rather, we developed new models using the same risk factors, plus the new variables (FH, exercise), and used arbitrary cut-off points for the reclassification analyses. Thus, while our models were calibrated for the study sample, the reclassification analyses may not have been based on optimal thresholds.

$\mathrm{FH}$ as a risk assessment tool has parallels with other genomic approaches to risk stratification. Online supplementary table 2 summarizes published analyses examining genetic polymorphisms added to standard risk factors for several complex disorders. These suggest that FH offers similar discriminative accuracy to genomic variants in complex disease risk assessment.

\section{Conclusions}

Our results indicate that $\mathrm{FH}$, when added to guidelinedefined risk factors, may offer statistically significant improvement in discrimination of risk of CHD in women (improvement in clinical validity), but its added value in risk discrimination is questionable. The impact of $\mathrm{FH}$ within risk prediction algorithms depends on how the reclassification of risk plays out in terms of the shifts in clinical and personal decision-making that result and how these translate into absolute gains in morbidity and mortality [25]. 


\section{Acknowledgements}

This work was supported by the Canadian Institutes of Health Research Grant ETG-92254. Q.H. was supported by University of Ottawa Admission and Graduate scholarships. Gordon Prescott provided support with extraction and interpretation of ASCHW data. J.L. holds a Canada Research Chair in Human Genome Epidemiology. Other members of the Emerging Team in Genomics are: Judith Allanson, Beth Potter, Holly Etchegary, George Wells, Mario Cappelli, David Castle, Denise Avard, Fiona A. Miller, Louise Lemyre, Karine Morin, Pranesh Chakraborty, and Silvia Visentin.

\section{References}

1 Hood L, Heath JR, Phelps ME, Lin B: Systems biology and new technologies enable predictive and preventative medicine. Science 2004; 306:640-643

2 Collins FS: Shattuck lecture-medical and societal consequences of the human genome project. N Engl J Med 1999;341:28-37.

-3 Guttmacher AE, Collins FS: Genomic medicine: a primer. N Engl J Med 2002;347:1512-1520.

4 Khoury MJ: Dealing with the evidence dilem$\mathrm{ma}$ in genomics and personalized medicine. Clin Pharmacol Ther 2010;87:635-638.

5 Khoury MJ: Genetics and genomics in practice: the continuum from genetic disease to genetic information in health and disease. Genet Med 2003;5:261-268.

-6 Rich EC, Burke W, Heaton CJ, Haga S, Pinsky L, Short MP, Acheson L: Reconsidering the family history in primary care. J Gen Intern Med 2004;19:273-280.

7 Yoon PW, Scheuner MT, Peterson-Oehlke KL, Gwinn M, Faucett A, Khoury MJ: Can family history be used as a tool for public health and preventive medicine? Genet Med 2002;4:304-310.

-8 Valdez R, Yoon PW, Qureshi N, Green RF, Khoury MJ: Family history in public health practice: a genomic tool for disease prevention and health promotion. Annu Rev Public Health 2010;31:69-87.

9 Qureshi N, Wilson B, Santaguida P, Little J, Carroll J, Allanson J, Raina P: NIH State-ofthe-Science Conference: Family History and Improving Health. Evidence Report/Technology Assessment No. 186. AHRQ Publication No. 09-E016. Rockville, MD, Agency for Healthcare Research and Quality, 2009.

10 Hariri S, Yoon PW, Moonesinghe R, Valdez R, Khoury MJ: Evaluation of family history as a risk factor and screening tool for detecting undiagnosed diabetes in a nationally representative survey population. Genet Med 2006; 8:752-759.

11 Scheuner MT, Setodji CM, Pankow JS, Blumenthal RS, Keeler E: General Cardiovascular Risk Profile identifies advanced coronary artery calcium and is improved by family history: the multiethnic study of atherosclerosis. Circ Cardiovasc Genet 2010;3:97-105.

$\checkmark 12$ Scheuner MT, Whitworth WC, McGruder H, Yoon PW, Khoury MJ: Familial risk assessment for early-onset coronary heart disease. Genet Med 2006;8:525-531.

-13 Berg AO, Baird MA, Botkin JR, Driscoll DA, Fishman PA, Guarino PD, Hiatt RA, Jarvik
GP, Millon-Underwood S, Morgan TM, Mulvihill JJ, Pollin TI, Schimmel SR, Stefanek ME, Vollmer WM, Williams JK: National Institutes of Health State-of-the-Science Conference Statement: Family History and Improving Health. Ann Intern Med 2009;151:872877.

14 Yeboah J, McClelland RL, Polonsky TS, Burke GL, Sibley CT, O'Leary D, Carr JJ, Goff DC, Greenland P, Herrington DM: Comparison of novel risk markers for improvement in cardiovascular risk assessment in intermediaterisk individuals. JAMA 2012;308:788-795.

15 Wilson BJ, Watson MS, Prescott GJ, Sunderland S, Campbell DM, Hannaford P, Smith WC: Hypertensive diseases of pregnancy and risk of hypertension and stroke in later life: results from cohort study. BMJ 2003;326: 845.

16 British Cardiac Society; British Hypertension Society; Diabetes UK; HEART UK; Primary Care Cardiovascular Society; Stroke Association: JBS 2: Joint British Societies' guidelines on prevention of cardiovascular disease in clinical practice. Heart 2005;91(suppl 5):v1v52.

17 Anderson KM, Wilson PW, Odell PM, Kannel WB: An updated coronary risk profile. A statement for health professionals. Circulation 1991;83:356-362.

18 Haq IU, Ramsay LE, Yeo WW, Jackson PR, Wallis EJ: Is the Framingham risk function valid for northern European populations? A comparison of methods for estimating absolute coronary risk in high risk men. Heart 1999;81:40-46.

19 Rose G, McCartney P, Reid DD: Self administration of a questionnaire on chest pain and intermittent claudication. Br J Prev Soc Med 1977;31:42-48.

20 Blackburn H, Keys A, Simone E, Rautaharju $\mathrm{P}$, Punsar S: The electrocardiogram in population studies. A classification system. Circulation 1960;21:1160-1175.

21 Pencina MJ, D’Agostino RB Sr, D’Agostino RB Jr, Vasan RS: Evaluating the added predictive ability of a new marker: from area under the ROC curve to reclassification and beyond. Stat Med 2008;27:157-172.

22 Wald NJ, Morris JK, Rish S: The efficacy of combining several risk factors as a screening test. J Med Screen 2005;12:197-201.

23 Wald NJ, Hackshaw AK, Frost CD: When can a risk factor be used as a worthwhile screening test? BMJ 1999;319:1562-1565.
24 Janssens AC, Khoury MJ: Assessment of improved prediction beyond traditional risk factors: when does a difference make a difference? Circ Cardiovasc Genet 2010;3:3-5.

25 Veenstra DL, Roth JA, Garrison LP Jr, Ramsey $\mathrm{SD}$, Burke W: A formal risk-benefit framework for genomic tests: facilitating the appropriate translation of genomics into clinical practice. Genet Med 2010;12:686-693.

26 Goff D: Adding systematic family history enquiry to cardiovascular disease risk assessment: clinical utility in primary care. Ann Intern Med 2012;157:148.

27 Bellamy L, Casas JP, Hingorani AD, Williams DJ: Pre-eclampsia and risk of cardiovascular disease and cancer in later life: systematic review and meta-analysis. BMJ 2007;335:974.

28 Samphier ML, Thompson B: The Aberdeen maternity and neonatal databank; in Mednik SA, Baert AE (eds): Prospective Longitudinal Research: An Empirical Basis for the Primary Prevention of Psychosocial Disorder. Oxford, Oxford University Press, 1981, pp 61-65.

29 Thompson B, Samphier M, Hall MH: The Aberdeen Obstetric Data Bank. Acta Genet Med Gemellol (Roma) 1979;28:375-376.

30 Aberdeen Maternity and Neonatal Databank. http://www.abdn.ac.uk/amnd/background. shtml (accessed September 2011).

-31 Fischbacher CM, Bhopal R, Unwin N, White M, Alberti KGMM: The performance of the Rose angina questionnaire in South Asian and European origin populations: a comparative study in Newcastle, UK. Int J Epidemiol 2001; 30:1009-1016.

-32 Russell M, Williams M, May E, Stewart S: The conundrum of detecting stable angina pectoris in the community setting. Nat Rev Cardio$\log 2010 ; 7: 106-113$.

-33 Lawlor DA, Adamson J, Ebrahim S: Performance of the WHO Rose angina questionnaire in post-menopausal women: are all questions necessary? J Epidemiol Community Health 2003;57:538-541.

-34 Owen-Smith V, Hannaford PC, Elliott AM: Increased mortality among women with Rose angina who have not presented with ischaemic heart disease. Br J Gen Pract 2003;53:784-789.

35 Schünemann HJ, Oxman AD, Brozek J, Glasziou P, Jaeschke R, Visit GE, Williams JW Jr, Kunz R, Craig J, Montori VM, Bossuyt P, Guyatt GH; GRADE Working Group: Grading quality of evidence and strength of recommendations for diagnostic tests and strategies. BMJ 2008;336:1106-1110. 